\title{
Grid Code compliance and ancillary services provision from DFIG and FRC-based wind turbines
}

\author{
Marios Michas \\ School of Engineering \\ Cardiff University, UK \\ MichasM@ cardiff.ac.uk
}

\author{
Carlos E. Ugalde-Loo \\ School of Engineering \\ Cardiff University, UK \\ Ugalde-LooC@ cardiff.ac.uk
}

\author{
Nick Jenkins \\ School of Engineering \\ Cardiff University, UK \\ JenkinsN6@ cardiff.ac.uk
}

\begin{abstract}
Wind power integration has been increasing over the recent years. Although a significant number of wind turbines (WTs) are AC connected to the grid either as fixed-speed induction generators or doubly fed induction generators (DFIGs), the use of permanent magnet synchronous generators (PMSGs) is being considered. As variable-speed WTs displace fossil fuel conventional plants, they are expected to comply with Grid Code requirements and contribute to the provision of ancillary services. In this paper, dynamic models and control schemes for DFIG and fully rated converter (FRC) PMSG-based WTs, rated at the same level, are presented. The dynamic responses and the fault ride-through capabilities of both technologies are assessed and compared. The inertia support capabilities of FRC PMSG-based WTs in the GB system have also been investigated.

Index Terms-Ancillary services, doubly fed induction generator, fault ride-through, fully rated converter, inertia response, permanent magnet synchronous generator, wind turbines.
\end{abstract}

\section{INTRODUCTION}

Grid integration of wind power has increased over the recent years. For instance, the installed capacity of wind generation in the UK is expected to increase up to $33 \mathrm{GW}$ by 2030, with a number of projects currently under construction or planned in the short term [1]. Wind farms are required to behave as much as possible as conventional power plants to support the network. As such, different studies are carried out on the capability of wind farms to provide ancillary services and to meet Grid Code requirements.

The oldest and simplest wind turbine (WT) technology is based on fixed-speed induction generators (FSIGs). The rotor speed is considered to be fixed, because the slip variations of the induction generator employed for this technology are very small (1-2\%). As the size of WTs increased, variable-speed operation technology was developed enabling the wind farms to meet Grid Code requirements. Two main technologies have been mainly employed for variable-speed operation: doublyfed induction generator (DFIG)-based and fully rated converter (FRC)-based WTs.

DFIG-based WTs constitute a well developed technology and many of the large WTs commercially available are of this type. In this technology, the mechanical frequency of the rotor is decoupled from the electrical frequency of the grid, enabling variable-speed operation. Differences between the responses of FSIG and DFIG-based WTs during changes in network frequencies have been highlighted in [2]. The stator of the generator is directly connected to the grid, enabling the
DFIG to provide a wider variety of ancillary services, such as frequency support [3] and damping of power oscillations of the AC grid [4].

The FRC-based WT configuration includes either an induction or a synchronous generator. However, permanent magnet synchronous generators (PMSGs) seem to be the most suitable machines, especially for high rated power WTs. With this technology the electrical excitation is replaced by a permanent magnet. Thus, the weight of the generator is reduced and the power losses associated with the rotor winding are eliminated. Additionally, the gearbox can be removed, reducing the failure rates of the WTs [5].

Since both technologies decouple the electrical frequency of the grid from the mechanical frequency of the generator, there is no inherent contribution to system frequency changes. As DFIG-based WTs have been replacing the conventional plants and possibly PMSG-based ones will do in future, the system inertia will inevitably decrease. Therefore, the rate of change of frequency $(\mathrm{RoCoF})$ following a frequency event becomes higher, highlighting the need for inertia support provision which could be contributed by wind farms [6], [7].

In this paper, dynamic models and control schemes for both DFIG and FRC PMSG-based WTs are presented and their ability to comply with the Grid Code in case of a voltage sag at the point of connection is investigated. A case study of FRC PMSG-based wind farms connected to the GB system and their impact on the frequency deviation following a considerable loss of generation is also considered.

\section{WIND TURBINE MODELS}

Detailed DFIG and PMSG-based WTs have been modelled using MATLAB/Simulink. Aerodynamic and drive-train models have been included to obtain more realistic configurations. The aerodynamic model was used for the implementation of the aerodynamic torque generated by the WT. Bladed, a commercial software, was employed to specify the power coefficient used for the calculation of the generated aerodynamic power for a practical $2 \mathrm{MW}$ WT, with parameters specified in Appendices A and B. The control schemes for the grid-side and the machine-side converters, a phase locked loop (PLL) and an optimum power extraction scheme have been included for completeness. 


\section{A. Aerodynamic model}

The aerodynamic torque $\tau_{\text {aero }}$ developed by the WT rotor is given by [8]

$$
\tau_{\text {aero }}=\frac{\rho A V_{w}^{3} C_{P}(\lambda, \beta)}{2 \omega_{\text {rot }}}
$$

where $\rho$ is the air density $\left(\mathrm{kg} / \mathrm{m}^{3}\right), A$ is the swept area of the rotor $\left(\mathrm{m}^{2}\right), V_{w}$ is the wind speed $(\mathrm{m} / \mathrm{s}), \omega_{\text {rot }}$ is the rotor speed $(\mathrm{rad} / \mathrm{s})$ and $C_{P}$ is the power coefficient which is a function of the blade pitch angle $\beta$ (deg) and tip speed ratio $\lambda$.

A simplified aerodynamic model, neglecting any dynamic inflow effects, wind shear or tower shadowing was used to convert wind energy to aerodynamic torque, as shown in Fig. 1. The power coefficient can either be obtained using a polynomial equation or a look-up table [8].

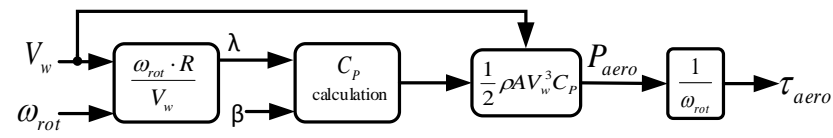

Fig. 1. Aerodynamic model.

\section{B. Drive-train model}

The torque developed by the WT is transferred to the generator shaft via the drive-train. It consists of an aerodynamic rotor, a low-speed shaft (LSS), a gearbox, a high-speed shaft (HSS) and a generator. A common way to model the drivetrain is through a number of masses separated by springs [9]. In this study, a three-mass model was adopted. The dynamic equations referred to the LSS are [10]

$$
\begin{gathered}
J_{1} \frac{d}{d t} \omega_{\text {rot }}=\tau_{\text {aero }}-K_{1}\left(\theta_{1}-\theta_{2}\right)-D_{1} \frac{d}{d t}\left(\theta_{1}-\theta_{2}\right) \\
J_{2} \frac{d}{d t} \omega_{\text {hub }}=-K_{1}\left(\theta_{2}-\theta_{1}\right)-K_{2}\left(\theta_{2}-\frac{\theta_{3}}{N}\right)+ \\
-D_{1} \frac{d}{d t}\left(\theta_{2}-\theta_{1}\right)-D_{2} \frac{d}{d t}\left(\theta_{2}-\frac{\theta_{3}}{N}\right) \\
J_{3} \frac{d}{d t} \omega_{g e n}=-\tau_{e m}-K_{2}\left(\frac{\theta_{3}}{N}-\theta_{2}\right)-D_{2} \frac{d}{d t}\left(\frac{\theta_{3}}{N}-\theta_{2}\right)
\end{gathered}
$$

where $J_{1}, J_{2}, J_{3}\left(\mathrm{~kg} \cdot \mathrm{m}^{2}\right)$ are the inertias of the flexible part of the blades, the hub and the rigid part of the blades and the generator, respectively; $K_{1}, K_{2}(\mathrm{~N} \cdot \mathrm{m} / \mathrm{rad})$ are the effective blade stiffness and the resultant stiffness of the LSS and HSS, respectively; $D_{1}, D_{2}(\mathrm{~N} \cdot \mathrm{m} \cdot \mathrm{s} / \mathrm{rad})$ are the effective blade and the resultant LSS-HSS dampings, respectively; $\omega_{\text {rot }}$, $\omega_{h u b}, \omega_{\text {gen }}(\mathrm{rad} / \mathrm{s})$ are the rotor, LSS and generator speeds, respectively; $N$ is the gearbox ratio and $\tau_{e m}(\mathrm{~N} \cdot \mathrm{m})$ is the electromagnetic torque.

\section{FRC-based WT configuration}

The topology of this WT is shown in Fig. 2. It consists of a PMSG and a power converter system consisting of two back-to-back voltage source converters (VSCs) connected to an infinite bus representing an AC grid. For the simulations, an ideal voltage source was used to represent the infinite bus.

The VSCs were modelled assuming ideal switching. The PMSG model in a $d q$ frame is given in [11] as

$$
\begin{gathered}
\frac{d}{d t} i_{d}=\frac{1}{L_{d}} u_{d}-\frac{R_{s}}{L_{d}} i_{d}+\frac{L_{q}}{L_{d}} n_{p p} \omega_{g e n} i_{q} \\
\frac{d}{d t} i_{q}=\frac{1}{L_{q}} u_{q}-\frac{R_{s}}{L_{q}} i_{q}+\frac{L_{d}}{L_{q}} n_{p p} \omega_{g e n} i_{d}-\frac{\psi_{m} n_{p p} \omega_{g e n}}{L_{q}} \\
\tau_{e m}=\frac{3}{2} n_{p p}\left[\psi_{m} i_{q}+\left(L_{d}-L_{q}\right) i_{d} i_{q}\right]
\end{gathered}
$$

where $L_{d}, L_{q}(\mathrm{H})$ are the self inductances of the stator; $R_{s}$ $(\Omega)$ is the stator resistance; $u_{d}, u_{q}(\mathrm{~V})$ are the stator voltages; $i_{d}, i_{q}$ (A) are the stator currents; $\psi_{m}(\mathrm{~V} \cdot \mathrm{m})$ is the flux linkage of the permanent magnet; $n_{p p}$ the pole pairs and $\omega_{g e n}$ is the generator mechanical speed $(\mathrm{rad} / \mathrm{s})$.

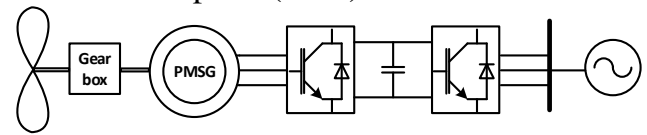

Fig. 2. FRC-based WT connected to infinite bus.

The control schemes in the $d q$ reference frame for both the generator-side and grid-side converters are described in detail in [10],[12] and illustrated in Figs. 3 and 4.

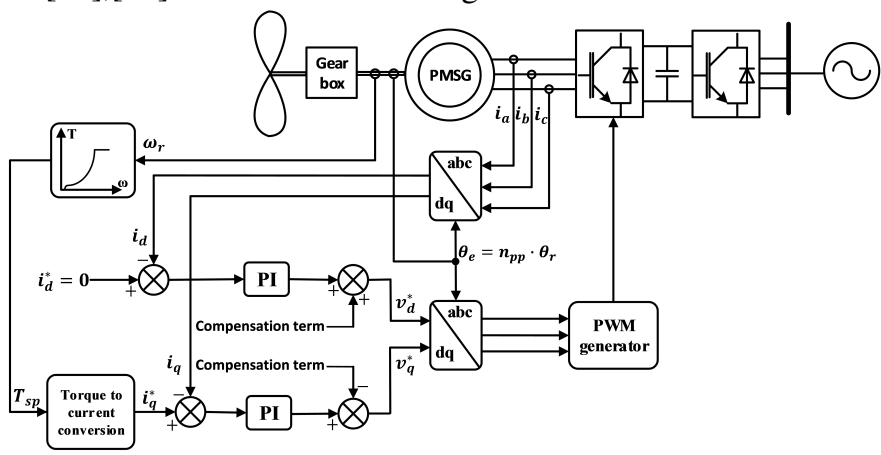

Fig. 3. Control scheme for the generator-side converter of the PMSG [12].

For the generator-side converter, the $q$-axis component of the current is used to control the torque. For a specific measurement of the generator speed $\omega_{r}$ (referred as $\omega_{\text {gen }}$ in the drive-train model), a reference set point for the torque is obtained through a look-up table, according to the characteristic for maximum power extraction. The reference value for the $q$-axis component of the current $i_{q}^{*}$ is then calculated and the difference with the measured value $i_{q}$ is fed to a PI controller. The sum of the output of the PI controller and a compensation (decoupling) term is the $q$-axis component of voltage $v_{q}^{*}$. On the other hand, the reference value for the $d$-axis component of the current $i_{d}^{*}$ is set to zero. The error between the reference value and the measured value $i_{d}$ is used as an input to a PI controller. The output of the PI controller is added to a compensation (decoupling) term and the $q$-axis component of voltage $v_{d}^{*}$ is obtained. The compensation terms mentioned above are included so that independent control of $d$ and $q$-axis is guaranteed. The resulting voltages $v_{q}^{*}$ and $v_{d}^{*}$ are transformed to the $a b c$ frame and the three-phase voltages are fed to a PWM generator.

For the grid-side converter, a PLL is employed to obtain the frequency used for the transformation of the current in the $d q$ frame. The $d$-axis component of the current is used to regulate 
the DC voltage. The reference value for the $q$-axis component of the current is set to zero, so that the reactive power is zero as WTs are mostly requested to operate at unity power factor.

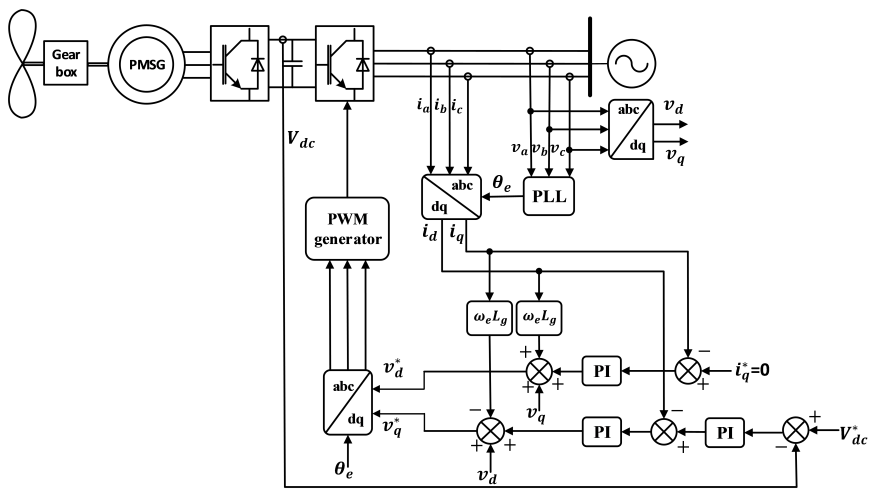

Fig. 4. Control scheme for the grid-side converter [13].

The difference between the reference value for the DC link voltage and the measured one is used as an input to a PI controller, so that the reference value for the $d$-axis component of the current is provided (outer loop). The difference between the reference value of the $d$-axis current and the measured one is processed by another PI controller (inner current loop). A feed forward term $\left(v_{d}\right)$ is added to the output of the inner current loop to improve the system response. Compensation (decoupling) terms are also used so that independent control of active and reactive power is ensured. The resulting voltages which are in the $d q$ frame are transformed to instantaneous voltage values which are used to generate the PWM signals for the converter [12].

\section{DFIG-based WT configuration}

Fig. 5 shows a DFIG-based WT connected to an infinite bus. A wound rotor induction generator is used and back-toback VSCs are implemented so that a controllable voltage is injected into the rotor winding at slip frequency.

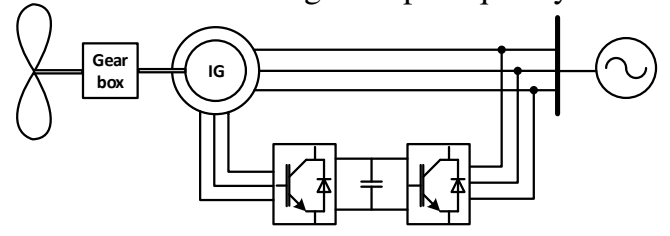

Fig. 5. DFIG-based WT connected to infinite bus.

The VSCs were modelled assuming ideal switching, as in the FRC topology. A per unit representation of the electrical model of the induction generator in a $d q$ frame has been adopted, given as [15]

$$
\begin{gathered}
\bar{v}_{d s}=-\bar{R}_{s} \bar{i}_{d s}-\bar{\omega}_{s} \bar{\psi}_{q s}+\frac{1}{\omega_{b}} \cdot \frac{d}{d t} \bar{\psi}_{d s} \\
\bar{v}_{q s}=-\bar{R}_{s} \bar{i}_{q s}-\bar{\omega}_{s} \bar{\psi}_{d s}+\frac{1}{\omega_{b}} \cdot \frac{d}{d t} \bar{\psi}_{q s} \\
\bar{v}_{d r}=\bar{R}_{r} \bar{i}_{d r}-s \bar{\omega}_{s} \bar{\psi}_{q r}+\frac{1}{\omega_{b}} \cdot \frac{d}{d t} \bar{\psi}_{d r} \\
\bar{v}_{q r}=\bar{R}_{r} \bar{i}_{q r}+s \bar{\omega}_{s} \bar{\psi}_{d r}+\frac{1}{\omega_{b}} \cdot \frac{d}{d t} \bar{\psi}_{q r} \\
\bar{T}_{e}=\frac{\bar{e}_{d} \bar{i}_{d s}+\bar{e}_{q} \bar{i}_{q s}}{\bar{\omega}_{s}}
\end{gathered}
$$

where $\bar{e}_{d}, \bar{e}_{q}, \bar{v}_{d s}, \bar{v}_{q s}, \bar{v}_{d r}, \bar{v}_{q r}(\mathrm{~V})$ are the internal, stator and rotor voltages; $\bar{i}_{d s}, \bar{i}_{q s}, \bar{i}_{d r}, \bar{i}_{q r}$ (A) are the stator and rotor currents; $\bar{\psi}_{d s}, \bar{\psi}_{q s}, \bar{\psi}_{d r}, \bar{\psi}_{q r}(\mathrm{~V} \cdot \mathrm{m})$ are the stator and rotor flux linkages; $\bar{R}_{s}, \bar{R}_{r}(\Omega)$ are the stator and rotor resistances; $\omega_{b}$, $\bar{\omega}_{s}$ are the base and synchronous speeds ( $\left.\mathrm{rad} / \mathrm{s}\right) ; s$ is the slip and $\bar{T}_{e}$ is the electromagnetic torque $(\mathrm{N} \cdot \mathrm{m})$.

The PV $d q$ control scheme [16] was chosen for the control of the DFIG. The control scheme for the rotor-side converter is described in detail in [17] and shown in Fig. 6.

The $q$-axis component of the rotor current is used to regulate torque. As shown in Fig. 6, for a specific measurement of generator rotor speed $\omega_{r}$ (referred as $\omega_{\text {gen }}$ in the drivetrain model), a reference set point for the torque is obtained through a look-up table, according to the characteristic for maximum power extraction. The reference value for the $q$-axis component of the rotor current $i_{q r}^{*}$ is then calculated and the difference with the measured value $i_{q r}$ is fed to a PI controller. The sum of the output of the PI controller and a compensation (decoupling) term is the $q$-axis component of the voltage $v_{q r}^{*}$ that is injected to the rotor winding.

The $d$-axis component current is used to regulate the terminal voltage. The difference between the reference and the measured value of the terminal voltage is used during the primary stage. A reference value for the $d$-axis component of the rotor current $i_{d r}^{*}$ is calculated and the difference with the measured value $i_{d r}$ is used as an input to a PI controller. The output of the PI controller is added to a compensation (decoupling) term and the $d$-axis component of the rotor voltage $v_{d r}^{*}$ is obtained.

The resulting voltages $v_{q r}^{*}$ and $v_{d r}^{*}$ are transformed to the $a b c$ frame using the slip frequency. The three-phase voltages are then fed to a PWM generator.

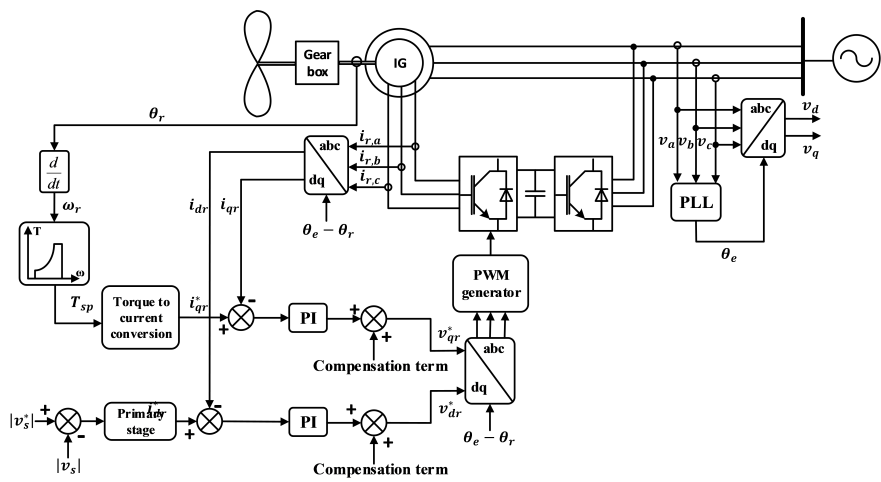

Fig. 6. Vector control scheme for the rotor-side converter of the DFIG [17].

The control strategy for the grid-side converter is similar as in the case of the FRC-based WT and therefore, no further discussion is warranted. However, the voltage used as an input to the PLL is measured in the branch just after the grid-side converter and not at the connection point.

\section{GRID CODE COMPLIANCE}

\section{A. UK Transmission System Operator requirements}

The fault ride-through requirements for WTs are specified by the Transmission System Operator (TSO) of each country. Although these vary from one country to another, turbines are expected to operate at a reduced voltage for a few milliseconds 
to several seconds. The fault ride-through capability demanded by the UK TSO is shown in Fig. 7 [18].

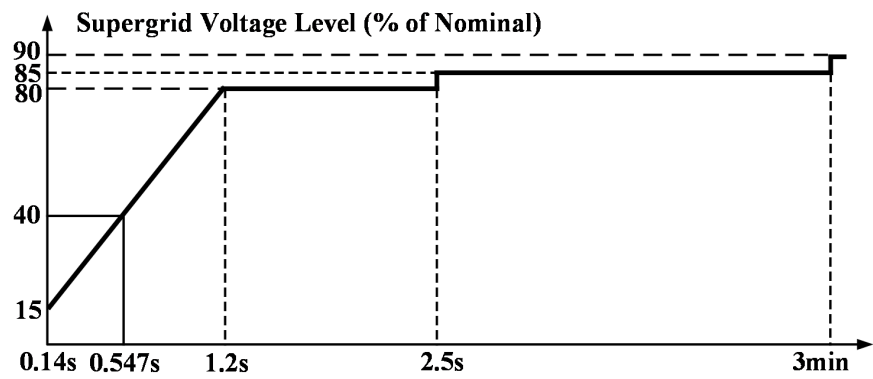

Fig. 7. Fault ride-through requirements defined by the UK TSO [18].

\section{B. Compliance of DFIG-based and FRC-based WTs}

The fault ride-through capability of a 2 MW DFIG-based and a 2 MW FRC-based WT models has been investigated. A voltage sag of $60 \%$ was applied at the infinite bus for 547 ms. Simulation results for both WT technologies are shown in Figs. 8 and 9. It can be seen that there is a larger impact on the DFIG torque rather than the FRC-based one. During the fault, there is a slight change in the torque provided by the PMSG. On the contrary, a peak of 3.5 p.u. is observed in the torque response of the DFIG. This is reasonable since the stator of the DFIG is directly connected to the grid, while the PMSG is electrically isolated from it. Additionally, the DC voltage response does not vary much for either configuration. Thus, it can be concluded that both technologies modelled in this work are capable of overcoming the voltage sag.

\section{INERTIA RESPONSE}

\section{A. Frequency in the GB power system}

The frequency of the GB power system in steady state is set at $50 \pm 0.5 \mathrm{~Hz}$. At present, the GB system is designed to retain stability of operation for a maximum loss of 1320 MW of generation, with the frequency limited to $-0.8 \mathrm{~Hz}$. An example of the frequency variation for a generation loss of $1320 \mathrm{MW}$ is illustrated in Fig. 10. In the future, the maximum loss of generation is expected to increase to $1800 \mathrm{MW}$ with the connection of larger generators, while a load of $60 \mathrm{GW}$ is expected to being served by 2020 [19].

According to Fig. 10, when a sudden failure in generation or a connection of a large load takes place the system frequency drops. The initial RoCoF is determined by the total inertia of the generators and spinning loads. TSOs have specified requirements regarding the provision of particular services in order for the frequency to be brought back to its nominal value. These services include the primary and the secondary frequency response. Primary frequency response can be defined as the immediate delivery of active power provided by a generation unit available between 10 and $30 \mathrm{~s}$ after the frequency event. After further frequency fall is prevented, secondary frequency response is provided: active power output increases and this lasts between $30 \mathrm{~s}$ and $30 \mathrm{~min}$ after the frequency event [20].
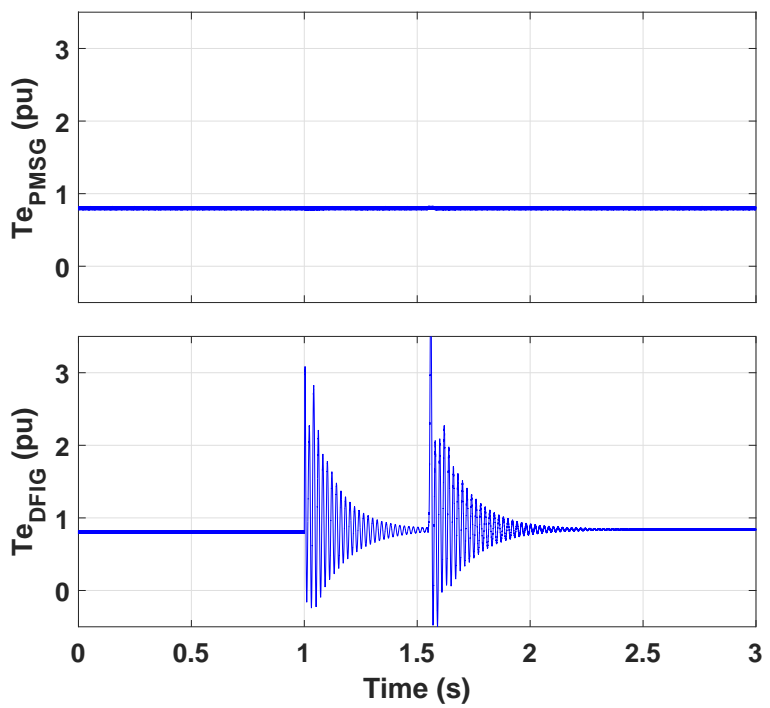

Fig. 8. PMSG and DFIG response under a $60 \%$ voltage sag for $547 \mathrm{~ms}$ : electromagnetic torque.
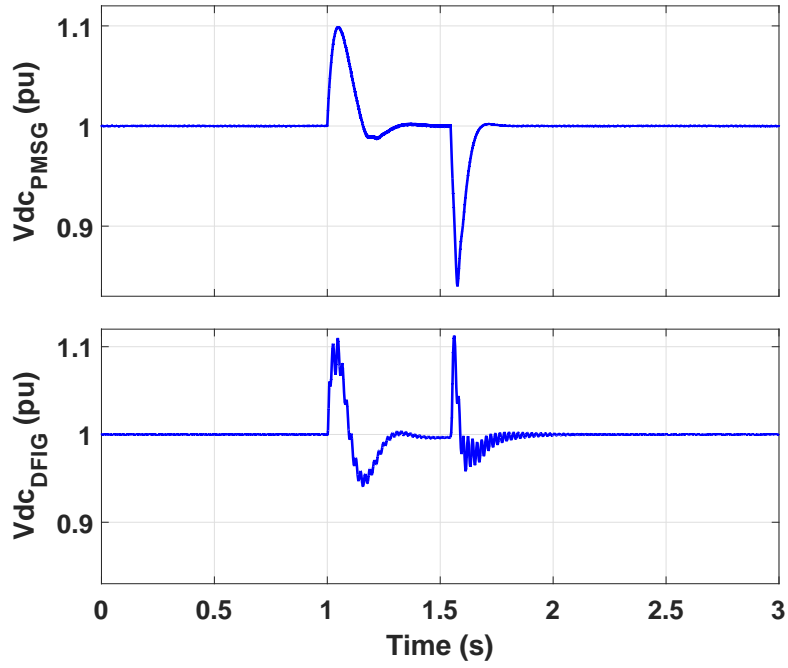

Fig. 9. PMSG and DFIG response under a $60 \%$ voltage sag for $547 \mathrm{~ms}$ : DV voltage.

In this work, the simplified model of the GB power system described in [21] was used, as shown in Fig. 11. Synchronous plants increase their output to respond to a drop in frequency. These responsive plants are represented by a governor droop $\left(1 / R_{e q}=-11\right)$, a governor actuator $\left(T_{G}=0.2 \mathrm{~s}\right)$ and a turbine $\left(T_{T}=0.3 \mathrm{~s}\right)$. A lead compensator is added for stability purposes $\left(T_{1}=2 \mathrm{~s}, T_{2}=12 \mathrm{~s}\right)$ between the governor and the turbine. The above parameters were obtained from [21]. The total inertia of the 2020 system has been calculated as $4.44 \mathrm{~s}$ [22].

The inertial contribution of FRC-based wind farms to the limitation of the RoCoF was assessed. A generation loss of $1.8 \mathrm{GW}$ in the GB system was assumed for the simulations.

\section{B. Inertial frequency response from offshore wind farms in the $U K$}

As wind integration increases, wind farms are expected to participate in the provision of ancillary services, like inertia 


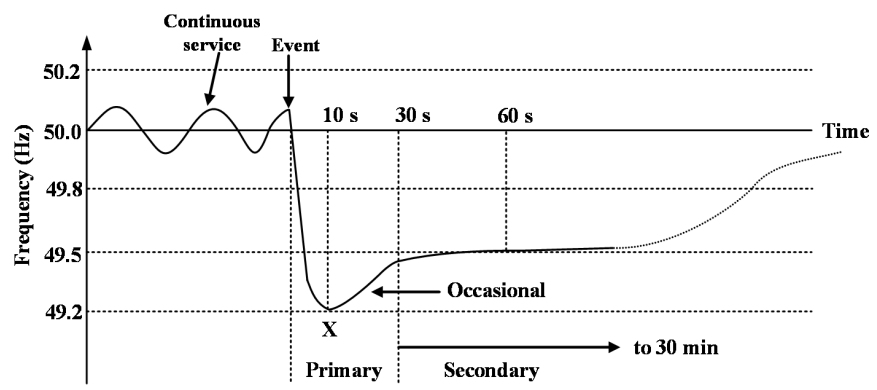

Fig. 10. Frequency deviation for a generation loss of 1320 MW [20].

response. To this end, different methodologies have been proposed, such as inertial coupling [3], [23] and step change in active power output [6], [24]. The main advantage of the first option against the later one is that through the inertial coupling the response of the machine can be very similar to the natural inertia. In fact, if an artificial inertia higher than the natural response is considered, the frequency response capabilities of the generator are bigger. On the contrary, applying a step change in the active power output of the generator and thus the torque reference can have a considerable impact on the mechanical stress applied on the shaft.

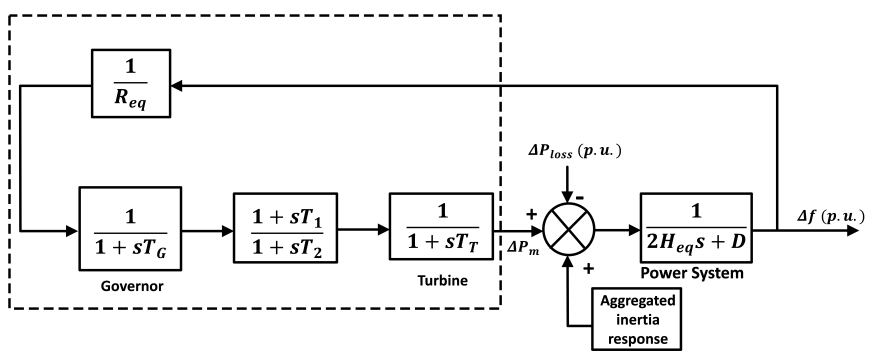

Fig. 11. Simplified GB power system model [21].

In this work, a supplementary control loop was added to the generator-side converter controller of the FRC-based WT, as shown in Fig. 12. This control scheme is used to extract the kinetic energy stored in the rotor of the PMSG.

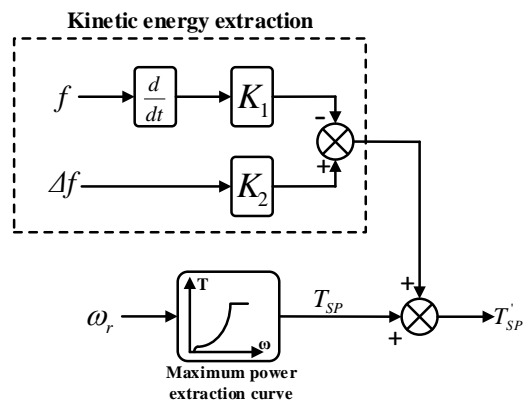

Fig. 12. Inertia response control scheme [24].

The total capacity of offshore wind farms (OWFs) connected to the GB system is approximately $4 \mathrm{GW}$. The provision of inertia response from OWFs in GB has been investigated based on the following assumptions: the offshore farms are based on 2 MW FRC-based WTs like the one described above; the WTs operate below rated speed; the wind speed is steady $(9.5 \mathrm{~m} / \mathrm{s})$ and applied to every single WT.

Fig. 13 shows the frequency deviation of the GB system for a generation loss of $1.8 \mathrm{GW}$ with inertia response (solid line) and without inertia response (dashed line). It can be seen that in case OWFs provide inertia response to the system the $\mathrm{RoCoF}$ decreases and the drop of frequency is limited to a higher value.

The impact of the additional control loop shown in Fig. 12 to the electromagnetic torque developed by the PMSG, the voltage of the DC link, and the additional power generated are illustrated in Fig. 14. A slight inscrease of the generated electromagnetic torque is observed, with a peak of 0.1 p.u. The variation of the voltage of the DC link is small, with a peak of $0.5 \%$ of the nominal value.

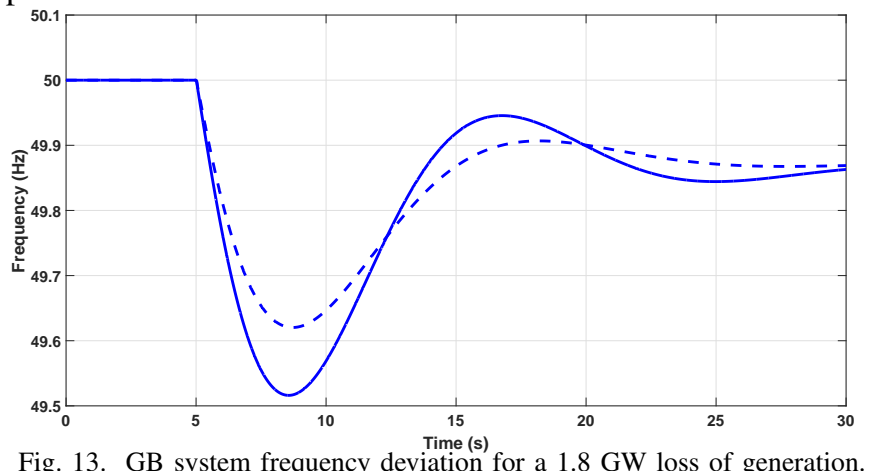

Fig. 13. GB system frequency deviation for a $1.8 \mathrm{GW}$ loss of generation.

In this case study, it was also assumed that all the WTs contribute equally to the inertia support. A more realistic study would include the implementation of wind farms based on different WT technologies considering different wind speeds and network characteristics. A more detailed study considering all these characteristics is out of the schope of this paper.

\section{CONCLUSION}

In this paper, control strategies for DFIG and FRC PMSGbased WTs have been reviewed and presented. Detailed WT models for both technologies considering aerodynamic and shaft flexibilities were implemented in order to assess the performance of the proposed strategies under voltage sag conditions at the point of connection with the grid. It is concluded that although there is a difference in their dynamic responses, both WT technologies comply with Grid Code requirements.

A simplified model for the frequency deviation of the GB system was used. The inertia response capabilities of FRC PMSG-based wind farms was investigated. The inertial coupling method was used to modify the generator-side converter controller of the each WT. The total capacity of these wind farms was assumed to be equal to the capacity of the installed OWFs in the UK. Results showing the overall contribution to the system inertia as well as the impact on the torque generation and the DC voltage deviation of each WT have been presented. It is seen that the RoCoF is limited to a higher value and the dynamic responses of the PMSG-based WTs are within acceptable limits.

Future work could be conducted towards the investigation of the inertia and frequency response of wind farms based 

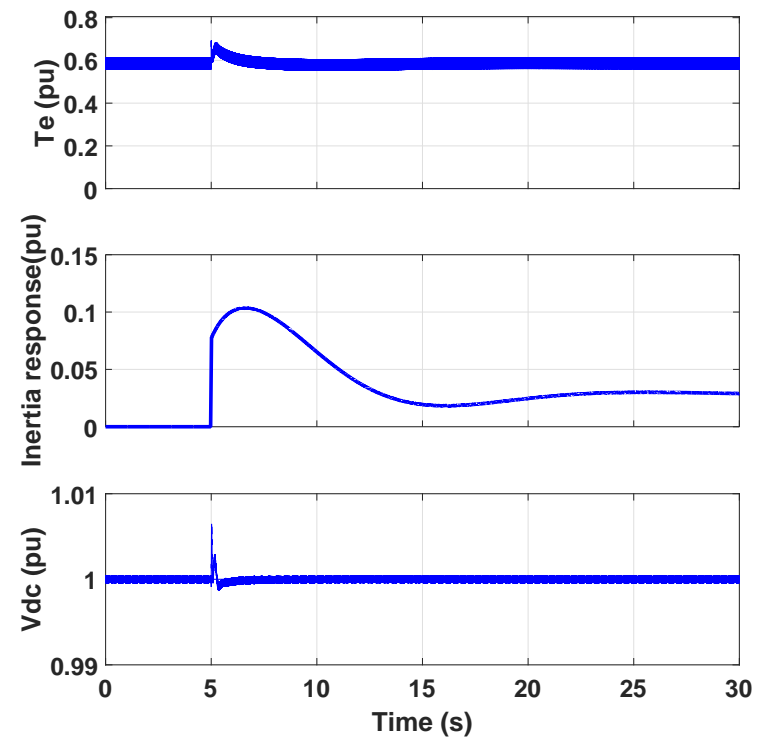

Fig. 14. Single FRC-based WT contribution to inertia response.

on both DFIG and FRC PMSG-based WTs. Different wind speeds and network characteristics could be considered.

\section{APPENDIX A: WIND TURBINES PARAMETERS}

Wind turbine: Power rating $=2 \mathrm{MW}$, rotor diameter $=40$ $\mathrm{m}$, rated speed $=18 \mathrm{r} / \mathrm{min}$, number of blades $=3$.

Three-mass model (referred to LSS): $J_{1}=2.227 \times 10^{6} \mathrm{~kg}$ $\cdot \mathrm{m}^{2}, J_{2}=3.801 \times 10^{6} \mathrm{~kg} \cdot \mathrm{m}^{2}, J_{3}=416633 \mathrm{~kg} \cdot \mathrm{m}^{2}, K_{1}=$ $573.18 \times 10^{6} \mathrm{~N} \cdot \mathrm{m} / \mathrm{rad}, K_{2}=1.6 \times 10^{8} \mathrm{~N} \cdot \mathrm{m} / \mathrm{rad}, D_{1}=0, D_{2}=$ $0, N=83.33: 1$.

PMSG: Poles: 4, frequency $=50 \mathrm{~Hz}, R_{s}=4.523 \mathrm{~m} \Omega$, $L_{d}=L_{q}=322 \mu \mathrm{H}, \psi_{m}=1.75 \mathrm{~V} \cdot \mathrm{s}$.

Induction Generator (in pu): $V_{b}=690 \mathrm{~V}, S_{b}=2$ MVA, $f_{b}=50 \mathrm{~Hz}, \omega_{b}=690 \mathrm{~V}, \bar{X}_{t r}=0.05, \bar{R}_{s}=0.00488, \bar{X}_{l s}=$ $0.09241, \bar{R}_{r}=0.00549, \bar{X}_{l r}=0.09955, \bar{R}_{d}=0.2696, \bar{X}_{l d}=$ $0.0453, \bar{X}_{m}=3.95279, \bar{X}_{r m}=0.02$.

Converters: DC link capacitor $(\mathrm{C})=90,000 \mu \mathrm{F}, V_{D C}=$ $1400 \mathrm{~V}$, switching frequencies $=3 \mathrm{kHz}$.

Grid: $V_{L L}=690 \mathrm{~V}$, grid coupling inductance $\left(L_{g}\right)=500$ $\mu$, grid coupling inductance $\left(R_{g}\right)=0.4 \mu \Omega$.

\section{APPENDIX B: CONTROL PARAMETERS}

DFIG rotor-side converter controller: $K_{P 1}=K_{P 2}=0.02$, $K_{I 1}=K_{I 2}=10$.

PMSG machine-side converter controller: $K_{P 1}=K_{P 2}=$ $0.476, K_{I 1}=K_{I 2}=280$.

Grid-side controller: $K_{P}=0.122, K_{I}=39.3$ (inner loop), $K_{P}=9.6, K_{I}=240$ (outer loop).

Inertia controller: $K_{1}=5000, K_{2}=3000$.

\section{ACKNOWLEDGMENT}

The authors would like to acknowledge the support from the Engineering and Physical Sciences Research Council (EPSRC), Research Councils U.K. (RCUK), through the grants Supergen+ for HubNet (EP/M015025/1) and HubNet (EP/I013636/1).

\section{REFERENCES}

[1] National Grid, Future Energy Scenarios, 2015.

[2] J.B. Ekanayake and N. Jenkins, "Comparison of the response of doubly fed and fixed-speed induction generator wind turbines to changes in network frequency", IEEE Trans. Energy Convers., vol. 19, no. 4, pp. 800-802, 2004.

[3] G. Ramtharan, J. B. Ekanayake, and N. Jenkins, "Frequency support from doubly fed induction generator wind turbines", Renew. Power Gener. IET, vol. 1, pp. 39, 2007.

[4] F. M. Hughes, O. Anaya-Lara, N. Jenkins and G. Strbac, "A power system stabilizer for DFIG-based wind generation", IEEE Trans. PowerSyst., vol. 21, no. 2, pp. 763-772, 2006.

[5] O. Anaya-Lara, N. Jenkins, J. B. Ekanayake, P. Cartwright, and M. Hughes, Wind energy generation. Modelling and control., John Wiley and Sons, 2011.

[6] M. Kayikci and J. V. Milanovic, "Dynamic contribution of DFIG-based wind plants to system frequency disturbances", IEEE Trans. Power Syst., vol. 24, no. 2, pp. 859867, 2009.

[7] Z. Wu, W. Gao, J. Wang, and S. Gu, "A coordinated primary frequency regulation from Permanent Magnet Synchronous Wind Turbine Generation", IEEE Power Electron. Mach. Wind Appl., pp. 16, 2012.

[8] S. Heier, Grid Integration of Wind Energy Conversion Systems, 2nd edition. John Wiley and Sons, 2006

[9] T. Burton, D. Sharpe, N. Jenkins, and E. A. Bossanyi, Wind Energy Handbook, 2nd ed. New York: Wiley, 2001.

[10] J. Licari, C. E. Ugalde-Loo, J. B. Ekanayake and N. Jenkins, ”Damping of torsional vibrations in a variable-speed wind turbine", IEEE Trans. Energy Convers., vol. 28, no. 1, pp. 172180, 2013.

[11] R. Krishnan, Permanent Magnet Synchronous and Brushless DC Motor Drives, 1st ed. New York: Taylor \& Francis, 2010.

[12] C. E. Ugalde-Loo, L. Amezquita-Brooks, E. Liceaga-Castro, and J. Liceaga-Castro, "Analysis and Efficient Control Design for Generatorside Converters of PMSG-based Wind and Tidal Stream Turbines",Proc. 18th PSCC, pp. 17,2014.

[13] J. Licari, C. E. Ugalde-Loo, J. Liang, J. B. Ekanayake, and N. Jenkins, "Torsional Damping Considering both Shaft and Blade Flexibilities", Wind Eng., vol. 36, no. 2, pp. 181196, 2012.

[14] J. Licari, "Control of a Variable-Speed Wind Turbine", 2013.

[15] J. B. Ekanayake, L. Holdsworth, X. Wu, and N. Jenkins, "Dynamic modeling of doubly fed induction generator wind turbines", IEEE Trans. Power Syst., vol. 18, no. 2, pp. 803809, 2003.

[16] R. Pena, J. C. Clare, and G. M. Asher, "Doubly fed induction generator using back-to-back PWM converters and its application to variable-speed wind-energy generation", IEE Proc. - Electr. Power Appl., vol. 143, no. 3, pp. 231-241, 1996.

[17] C. E. Ugalde-Loo, J. B. Ekanayake and N. Jenkins, "State-space modeling of wind turbine generators for power system studies", IEEE Trans. Ind. Appl., vol. 49, no. 1, pp. 223232, 2013.

[18] National Grid Electricity Transmission, "The Grid Code", Revision 15, no. $5,2016$.

[19] "Local authority CO2 emissions estimates 2006", Stat. Summ. 2018.

[20] I. A. Erinmez, D. O. Bickers, G. F. Wood, and W. Hung, "NGC experience with frequency control in England and Wales-provision of frequency response by generators", IEEE Power Eng. Soc. 1999 Winter Meet. (Cat. No.99CH36233), vol. 1, pp. 590596, 1999.

[21] Y. Mu, J. Wu, J. B. Ekanayake, and N. Jenkins, "Primary Frequency Response From Electric Vehicles in the Great Britain Power System", vol. 4 , no. 2 , pp. $19,2013$.

[22] J. B. Ekanayake, N. Jenkins and G. Strbac, "Frequency response from wind turbines", Wind Eng., vol. 32, pp. 573586, 2008.

[23] J. F. Conroy and R. Watson, "Frequency response capability of full converter wind turbine generators in comparison to conventional generation", IEEE Trans. Power Syst., vol. 23, no. 2, pp. 649656, 2008.

[24] N. R. Ullah, T. Thiringer, and D. Karlsson, "Temporary Primary Frequency Control Support by Variable Speed Wind Turbines-Potential and applications", IEEE Trans. Power Syst., vol. 23, no. 2, pp. 649-656, 2008.

[25] J. Licari, J. B. Ekanayake, and I. Moore, "Inertia response from fullpower converter-based permanent magnet wind generators", Journal of Modern Power Systems and Clean Energy, vol. 1, no. 1, pp. 2633, 2013. 